\title{
NOVAS TENDÊNCIAS NO ESTUDO DO \\ CONHECIMENTO, ECONOMIA \& SOCIEDADE
}

por Christiana Freitas*

CURRENT SOCIOLOGY. New directions in the study of Knowledge, Economy and Society. Oxford, v. 49, n. 4, july, 2001. Monograph 2 Edited by Kamini Adhikar and Arnaud Sales.

A edição especial de Current Sociology, intitulada "New directions in the study of Knowledge, Economy and Society" (Novas direções no estudo do conhecimento, economia e sociedade), foi organizada por K. Adhikari e A. Sales e oferece ao leitor instigantes questões para reflexão. Duas delas foram frequientemente incorporadas às intenções de grande parte dos artigos. Em primeiro lugar, quais os caminhos das sociedades contemporâneas, transformando e sendo transformadas por contextos inovadores nos campos da economia e do conhecimento? Além da análise e exposição de conceitos para a compreensão da realidade atual, alguns artigos sugerem, ainda, estratégias de ação visando à intervenção no contexto socioeconômico-informacional hoje vivido. Portanto, a segunda questão poderia ser formulada segundo imperativos práticos, objetivando estimular a atuação dos pesquisadores como agentes produtores não só de análises, mas também de mudanças. Nesse caso, a pergunta seria: o que podemos fazer para alterar situações não condizentes com práticas democráticas?

A revista é constituída por três grandes conjuntos de trabalhos, sendo o primeiro aquele dedicado às discussões teóricas relativas à

\footnotetext{
"Doutoranda do Departamento de Sociologia da UnB; em fase de conclusão da tese, intitulada Práticas sociais no ciberespaço e as redes acadêmicas virtuais.
} 
criação e incorporação do conhecimento às atividades socioeconômicas da atualidade.

O primeiro artigo, de Knorr Cetina \& Preda, "The epistemization of economic transactions" (A epistemologização das transações econômicas), tem como uma de suas intenções principais questionar argumentos que caracterizam o contexto atual, denominando-o a partir de termos como sociedade do conhecimento ou sociedade da informação. Interessante ressaltar a contribuição do artigo no que se refere à explicação da pervasividade do conhecimento científico nos dias de hoje (Castells, 1999). Significa dizer que tal conhecimento penetra em todas as esferas da sociedade; não apenas os produtores diretos de ciência estão com ela envolvidos, mas grande parte dos atores sociais, destacando-se, aqui, aqueles do campo econômico.

$\mathrm{O}$ artigo defende a necessidade de pesquisas empíricas que penetrem no processo de produção do conhecimento, ao invés de fornecer visões externas simplificadas a respeito do mesmo, não explorando a construção de sistemas específicos que tal produção engendra. Para tanto, propõem uma "teoria interiorizada do conhecimento". Até então, tal proposta não se diferencia daquelas já conhecidas no campo da Sociologia da Ciência, integrantes da teoria construtivista. Os autores inovam quando sugerem a reflexão segundo uma “dimensão analítica das práticas epistêmicas, através das quais os objetos econômicos (como, por exemplo, países ou fatos associados às dinâmicas de mercado) e transações são, eles mesmos, penetrados e transformados" (p. 7). Para além da confusa noção de práticas epistêmicas, que nada mais seria, para os autores, do que a prática com base na "observação e coleta contínuas de informação", propõem, ainda, o reconhecimento da produção do conhecimento referenciado em uma epistemologização das transações econômicas. À primeira vista, temos a impressão de que toda a sociedade civil alvoroça-se, hoje em dia, a analisar o processo de produção do conhecimento científico, suas tendências e caminhos traçados ao longo da história, papel da epistemologia por definição. ${ }^{1}$ Mas não, tal expressão referese a um "processo social de trabalho inscrito em e constitutivo de 
objetos econômicos relevantes para as atividades práticas de agentes econômicos" (p. 31). Um processo social envolvendo transações econômicas epistemológicas? O objetivo do artigo é mais simples do que parece: demonstrar empiricamente como práticas econômicas envolvem produção, uso e distribuição de conhecimento nãoacadêmico, e não apresentar agentes econômicos como epistemólogos, analistas do conhecimento. Utilizam e produzem conhecimento específico, o que é bastante diferente de um esforço analítico visando à compreensão da história e validade do conhecimento científico. Seria interessante cautela maior no uso de termos que não parecem conhecidos dos autores em questão. Fica difícil prestar atenção no conteúdo empírico, relevante, do artigo, com tantas propostas conceituais questionáveis.

$\mathrm{O}$ artigo de Hage, "Adaptative costs: a new institucional paradigm of rules for the competitive games" (Custos adaptativos: um novo paradigma institucional de regras para o jogo competitivo), constata a emergência de um novo paradigma institucional tendo, como ponto de partida, alterações recentes nas regras de competição do mercado internacional. O campo da economia estaria num processo de transição, passando da competição via produtividade para a competição via inovação. Essa inovação, entretanto, adquire aqui significado mais complexo que o tradicional conceito associado ao termo, cuja referência encontra-se na criação de um novo produto para a satisfação de demandas mercadológicas. Atualmente, tal conceito abrangeria uma série de outras questões complexas, como a garantia da qualidade do produto, concentrando-se em características como a durabilidade e baixos custos operacionais; a descoberta de novas partes componentes de produtos novos ou já existentes e a atenção à redução de aspectos negativos da produção como, por exemplo, prejuízos ao meio ambiente e à saúde humana.

O objetivo do trabalho é expor as premissas desse novo modelo, com base nos conceitos de "custo e benefício adaptativos". Tais custos adaptativos refletiriam custos de controle e monitoramento dos ambientes científicos, tecnológicos e competitivos relacionados às empresas; gastos com o desenvolvimento de produtos inovadores complexos e custos de erro, resultado do lançamento tardio ou precipitado de produtos no mercado. A preocupação das empresas 
com esses riscos, ou custos adaptativos, gera a formação de redes interorganizacionais, alianças estratégicas ou joint ventures, como caminho para redução dos custos. É com base nessa tendência que o autor defende a emergência de uma nova lógica competitiva e, com isso, um novo paradigma institucional. A reunião das empresas em conglomerados oferece inúmeras vantagens às mesmas, ou "benefícios adaptativos". Dentre eles, destaca-se o aumento do valor do conhecimento tácito estocado, armazenado nas empresas e posteriormente compartilhado com as demais. Além disso, a possibilidade do financiamento de pesquisas conjuntas e a construção de uma posição mais sólida no mercado por parte das empresas, que se associam a outras, também são fatores considerados como vantagens dessa nova configuração. As relações interorganizacionais são privilegiadas na análise, tornando o trabalho fonte importante de dados acerca da situação atual da economia contemporânea em estreita relação com o conhecimento e o seu papel no presente.

O artigo seguinte, de Bellon \& Niosi, "Institutionalist theories and inter-firm alliances: the transaction cost, competence and evolutionary debate revisited" (Teorias institucionalistas e alianças entre empresas: a transação custo, competência e debate evolucionista revista), discute o mesmo tema e conceitua termos empregados no artigo anterior. Alianças entre empresas, por exemplo, referem-se a acordos cooperativos específicos, estabelecidos entre duas organizações independentes, sejam elas empresas ou laboratórios públicos. Aquilo que no artigo anterior havia ficado pouco explicado, como o detalhamento das especificidades de joint ventures quando comparadas a outras redes estabelecidas no passado, encontra nesse trabalho espaço para respostas. O que torna tais alianças radicalmente distintas das redes estabelecidas anteriormente é o seu caráter nãohierárquico. Significa que as organizações envolvidas permanecem independentes, todos os parceiros têm seus recursos comprometidos nos empreendimentos e os objetivos da coalizão implicam processo conjunto visando à inovação e desenvolvimento. Ao mesmo tempo, tais consórcios colaboram para a redução dos riscos de cada empresa ou organização envolvida, riscos estes intensificados com o processo de globalização e liberalização dos mercados. O trabalho de Bellon $\&$ Niosi confere evidências empíricas adicionais às características e 
tendências explicitadas por Hage anteriormente. Na década de 80, por exemplo, pesquisas apontaram a existência de 10.000 alianças entre corporações européias e entre empresas européias e nãoeuropéias (Coombs et al., 1996, p. 167).

No artigo intitulado "How the law works: exploring the implications of emerging intellectual property regimes for knowledge, economy and society" (Como a lei funciona: explorando as implicações das leis emergentes de propriedade intelectual para o conhecimento, economia e sociedade), Polster trata das leis que regulamentam questões referentes à propriedade intelectual, sendo de fundamental importância para a compreensão da relação entre os campos do conhecimento científico, economia, sistema jurídico e sociedade. Trata, principalmente, das conseqüências de tais leis nas práticas de produção do conhecimento na atualidade. A tese do artigo centra-se na demonstração dos mecanismos através dos quais as leis que regulam o tema da propriedade intelectual interferem nas condições atuais de países distintos, com conseqüências mais ou menos devastadoras, intensificando padrões de desigualdade entre nações. A autora aponta motivos convincentes para afirmar que tais leis podem, indiretamente, impedir o desenvolvimento econômico, resultando em possível limitação do uso de recursos aplicados à inovação, erosão de processos democráticos e cerceamento à livre produção científica nas universidades. Além disso, os custos para incorporação ou utilização de pesquisas e produtos são significativamente mais elevados quando estes se submetem às regulamentações que os definem segundo leis de propriedade intelectual, comprometendo ainda mais a situação desfavorável dos países em desenvolvimento. Tais leis são analisadas segundo suas implicações negativas para os caminhos do conhecimento, economia e sociedade, restando, no artigo, pouco espaço para possíveis vantagens advindas das novas regulamentações.

A segunda parte da revista analisa tendências relativas às profissões, com base na incorporação do conhecimento formal organizado segundo interesses específicos.

$\mathrm{O}$ artigo de Brint, "Professionals and the "Knowledge Economy': rethinking the theory of postindustrial society" (Profissionais e Economia do Conhecimento: repensando a teoria da 
sociedade pós-industrial), pretende reavaliar teorias que rotulam a sociedade atual de formas variadas, iniciando o debate com uma reflexão acerca das noções referentes à economia do conhecimento. Três correntes teóricas são destacadas: aquelas que enfatizam o gerenciamento da inovação em corporações maduras; idéias que realçam o surgimento de serviços ao consumidor e da indústria de alta tecnologia, bem como aquelas que lidam prioritariamente com os serviços financeiros. $\mathrm{O}$ artigo sugere uma reunião ou conjugação das teorias mencionadas, visando à obtenção de análises mais acuradas relativas ao papel dos profissionais no contexto em questão. $\mathrm{O}$ artigo realiza estudo sobre as indústrias que empregam uma proporção comparativamente grande de profissionais com diplomas de nível superior, a fim de traçar os limites da chamada "economia do conhecimento formal". Os setores que participam dela incluem as indústrias de serviços, de alta tecnologia, os serviços profissionais, as áreas do governo e algumas indústrias de mass media. Ao contrário dos artigos vistos até agora, onde o conhecimento é percebido como pervasivo, constituinte dos processos de manutenção e transformação das sociedades contemporâneas nas mais variadas esferas, Brint afirma que a economia com base no conhecimento formal ainda não penetrou em todos os setores industriais atualmente existentes. Isso porque representa, mesmo com sua crescente importância no contexto da economia norte-americana, apenas dois quintos do Produto Nacional Bruto (PNB) dos Estados Unidos. Nem todos os trabalhadores, inclusive, apresentam formação adequada para permitir a franca expansão desse processo. Segundo dados obtidos na pesquisa realizada, apenas $55 \%$ de todos os profissionais no setor da economia possuem diplomas de nível superior. Apesar de permanecer a dúvida com relação à sustentabilidade das afirmações com base nos dados apresentados, o artigo é instigante, exemplo de um trabalho empírico bem realizado.

O artigo de Evetts \& Buchner-Jeziorska, intitulado "The professionalization of knowledge in European markets: Engineering in the UK and Poland" (A profissionalização do conhecimento nos mercados europeus: Engenharia no Reino Unido e na Polônia), apresenta um estudo de caso reunindo a situação das associações regionais de profissionais de engenharia, na Europa, e uma nova configuração social: as novas associações profissionais internacionais. 
A intenção é perceber como o conhecimento é controlado, reproduzido e transformado nessas instituições. Além disso, os autores focalizam os elementos dinâmicos da influência e controle institucional sobre as práticas profissionais no curso da internacionalização da produção econômica. $\mathrm{O}$ artigo realiza uma análise interessante a respeito das repercussões do processo de internacionalização das profissões no contexto regional dos países analisados, concluindo que tal internacionalização, característica considerada central no processo de profissionalização, não se dá de maneira uniforme, mas varia de acordo com condições de interação e características institucionais específicas encontradas em cada região pesquisada.

A seguir, em "Professional group power in developing societies" (Poder de grupos profissionais em sociedades em desenvolvimento), Krause analisa o contexto das profissões a partir de constatações empíricas, observando e questionando a situação de profissionais nos países em desenvolvimento, caracterizados por um Estado frágil que, por esse motivo, não forneceria garantias para a construção de atividades autônomas. O Estado, segundo a pesquisa, não possuiria independência suficiente para tanto. Cabe sublinhar que o autor inicia o artigo já partindo do pressuposto de que caberia ao Estado oferecer tais garantias aos profissionais. A tese central do artigo de Krause baseia-se na suposição de que "uma independência gradual dos Estados em desenvolvimento, se alcançada, pode rapidamente levar à dependência das profissões com relação aos capitalistas, que possuem um motivo próprio, centrado no lucro, para tais investimentos, e não o desenvolvimento de instituições profissionais fortes” (p. 231).

$\mathrm{O}$ artigo peca por um reducionismo simplificador do qual o autor lança mão algumas vezes, reducionismo este presente em afirmações do tipo: "o êxito mundial do capitalismo está criando o mesmo tipo de pressão por todas as partes: as profissões estão sendo reformadas gradualmente de uma maneira mais capitalista, os profissionais trabalham para os donos dos meios de produção, e não para si mesmos" (p. 231). Ora, esse fenômeno não é novidade da etapa histórica em que o mundo se encontra, mas constitui o cerne de formação do sistema capitalista. Não fica claro, portanto, qual a contribuição desse trabalho para a análise atual dos variados contextos especificados nos outros artigos da revista. Ademais, o tipo de controle 
exercido sobre as profissões, atualmente, não depende apenas do tipo de Estado em vigor, em países distintos, como o autor sugere; o fato de um Estado ser antidemocrático, pseudodemocrático ou algum outro termo que o caracterize não pode ser visto como único fator a conduzir o futuro das profissões. Hão de se levar em consideração inúmeros fatores conjugados, como: demandas de mercado e verbas disponíveis, resultado não só de políticas estatais adotadas mas também de aspectos presentes nos demais campos da sociedade.

$\mathrm{O}$ artigo de Fuller, "A critical guide to knowledge society newspeak: or, how not to take the great leap backward" (Um guia crítico a respeito do discurso sobre a sociedade do conhecimento: ou, como não dar um salto para trás), inicia a terceira e última parte dessa edição especial de Current Sociology. O principal objetivo do trabalho é criticar as várias versões e interpretações relativas à sociedade atual, rotulando-a de "sociedade do conhecimento". O autor chega a afirmar que esse termo "parece fascinar os teóricos sociais porque finalmente foram incorporados ao modo de produção capitalista" (p. 233). Sua crítica, por vezes irônica, é também contundente e bem fundamentada. O conhecimento transforma-se em mercadoria, sujeito às forças de mercado e não a normas e práticas que tradicionalmente o caracterizavam, tais como aquelas apontadas por Merton como "os imperativos institucionais da ciência", dos quais fazia parte o desinteresse como característica básica da produção científica.

Fuller critica não só o tratamento dado ao conhecimento de forma geral como também as instituições que o produzem, considerando-as espaços destinados ao gerenciamento puro e simples do conhecimento. Tal contexto implica a formação de novos atores sociais: os administradores do conhecimento (knowledge managers). As universidades passam a produzir conhecimento de forma mecânica e quase automatizada, servindo a objetivos mercadológicos. O autor analisa três tendências atuais que fundamentam sua afirmação: "a necessidade de referências para obtenção de emprego, o desenvolvimento de expert systems e a expansão da legislação aplicada à propriedade intelectual" (p. 180). Tem-se a impressão de que Fuller realiza a crítica coerente e acertada que Krause tenta fazer sem sucesso. 
"Is knowledge-based society a relevant strategy for civil society?" (Uma sociedade baseada no conhecimento pode ser uma estratégia pertinente para uma sociedade civil?). Esse é o título e pergunta central do último artigo considerado. Esse trabalho apresenta a mesma intenção verificada em grande parte dos artigos precedentes: sublinhar a necessidade de repensar conceitos já existentes para a transformação de realidades sociais insatisfatórias gerando, entre outras consequiências, desigualdades entre nações. No caso do artigo de Hayrinen-Alestalo, o conceito a ser repensado é o de "responsabilidade coletiva", para que seja possível a construção de uma "sociedade da informação inclusiva". A autora critica os rumos tomados pela "sociedade da informação" regida pelo paradigma tecnoeconômico, mesmo não explicando convenientemente o que vem a ser o termo, ou qual das correntes é adotada para a consecução do artigo. Aponta nefastos resultados desse contexto segregacionista, dentre eles o surgimento de novas hierarquias e formas de exclusão, resultantes de elementos competitivos - como eficiência e controle compondo o paradigma vigente. Questiona o fracasso das tentativas de criação de um contexto societário que inclua a todos, analisando a transição de objetivos adotados por governos atuais. Anteriormente, o Estado objetivava "controlar e desenvolver a democratização do processo de modernização através da igualdade de oportunidades" (p. 203). Atualmente, as tentativas teoricamente democráticas de construção de sociedades igualitárias vêm sendo substituídas, na prática, por visões instrumentalistas, onde conhecimento, informação, educação e solidariedade são utilizados para fins mercadológicos.

Percebe-se, como característica comum aos artigos publicados nessa edição especial de Current Sociology, a análise das mudanças relativas ao processo de produção, uso e distribuição do conhecimento científico e não-científico, observando a penetração dos mesmos nas variadas esferas da sociedade, principalmente no campo relativo às práticas econômicas. Quase todos os autores afirmam o caráter de transitoriedade e constante mutação da sociedade do conhecimento atual, questionando termos aplicados à sua compreensão. Além da exposição crítica de categorias analíticas, relevantes para a reflexão relacionada às teorias construídas a respeito das transformações societárias atuais, processos inter-relacionais são desvelados e 
observados, visando não apenas à compreensão dos contextos socioeconômicos contemporâneos, mas também à construção de conceitos que viabilizem a atuação dos indivíduos em realidades que, porventura, precisem ser reavaliadas e transformadas.

\section{Nota}

1 Epistemologia é caracterizada como "o estudo do grau de certeza do conhecimento científico em seus diversos ramos" (Bueno, 1975, p. 500). 